\title{
Pratifine Heberiat
}

ber vorzủgliduten

\section{Secilquellen Tentifhlands}

nad cignen Erfabrungen

$\boldsymbol{\bullet} \boldsymbol{n}$

\section{Dr. Chrift. SBilf. Şufelats,}

Ronigl. Preug. Staateratg, exftem Reibarzt, Ritter Deb rotben Zloler = Sroene erfter Silafie $k$.

$$
\begin{gathered}
\text { Serausgegeben unb ergangt } \\
\text { yon }
\end{gathered}
$$

Fipe. C. $D$ f $\mathrm{An}$,

Rinigl. Preuf. Oefl. Med.: Rath, Profeffor, Ritter bes rotben 2olerordens britter Filafie mit Der Sdleife te.

Bierte vermebrte Auflage.

\section{Berlin 1840.}

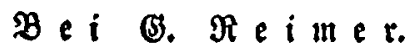


